\title{
PENERAPAN FRAMEWORK IONIC DALAM PERANCANGAN APLIKASI E-CONCEPT SEBAGAI ALAT TERUKUR DALAM PEREKRUTAN SIMPATISAN PEMILUKADA
}

\author{
Mustazzihim Suhaidi ${ }^{1)}$, Nurhadi $^{2)}$, dan Latip ${ }^{3)}$ \\ ${ }^{1}$ Teknik Informatika, Sekolah Tinggi Teknologi Dumai \\ ${ }^{2}$ Teknik Informatika, STMIK Dumai \\ ${ }^{3}$ Ilmu Administrasi Negara, STIA-LK Dumai \\ ${ }^{1}$ Jl. Utama Karya Bukit Batrem No. 06 Dumai Timur Kota Dumai, Riau 28826 \\ ${ }^{2}$ Jl. Utama Karya No. 04 Bukit Batrem Dumai Timur Kota Dumai, Riau 28826 \\ ${ }^{3}$ Jl. Gunung Merapi No.1 Bumi Ayu Dumai, Riau 28825 \\ E-mail : muja.1708@gmail.com ${ }^{1)}$, flinkdumai@gmail.com ${ }^{2}$, latip.stiadmi@gmail.com ${ }^{3)}$
}

\begin{abstract}
ABSTRAK
Salah satu bentuk dari Gerakan Reformasi adalah pelaksanaan Pemilihan Umum Kepala Daerah (Pemilukada) baik di tingkat kabupaten, kotamadya maupun provinsi yang dilaksanakan secara langsung. Implikasi dari pelaksanaan pemilukada langsung adalah semakin banyaknya calon - calon yang bermunculan, terlebih ketika dibukanya peluang bagi calon perseorangan (independen) untuk ikut berlaga memperebutkan sebagai pemenangnya. Dengan jumlah penduduk yang besar, sosial kemasyarakatan yang beragam, dan ketatnya persaingan, menjadikan Pemilukada sebuah proses yang menghabiskan energi dan tentu biaya besar. Dalam pandangan masyarakat, semakin banyak calon berarti semakin banyak pilihan. Sebaliknya, bagi para kandidat berarti persaingan yang semakin ketat. Butuh desain strategi yang jitu dan tepat agar perjalanan menuju kantor bupati atau walikota, gubernur bisa lebih efektif dan efisien. Data merupakan aset yang paling berharga pada saat kampanye atau sosialisasi karena dapat berfungsi sebagai alat utama sebuah indikator keberhasilan dan pencapaian target kampanye sebagai bahan pertimbangan dalam mengambil keputusan, terutama meningkatkan efisiensi biaya dan efektifitas gerakan Tim Kampanye. E-Concept adalah Software Aplikasi alat ukur dalam perekrutan simpatisan Pemilukada yaitu sebagai alat ukur untuk memenangkan pemilu/pilkada dengan memanfaatkan teknologi informasi dan komunikasi dalam pengolahan data serta teknik statistika dalam membaca dan mendesain prediksi peluang bagi calon atau kandidat. Ionic Framework merupakan salah satu solusi yang dapat dipergunakan, dimana penggunaan Ionic Framework memungkinkan pengembang membuat aplikasi untuk beberapa platform dengan hanya menggunakan bahasa pengembangan web untuk membuat sebuah aplikasi mobile, sehingga dapat meminimalkan waktu dan biaya dalam proses pengembangan sistem berikutnya.
\end{abstract}

Kata Kunci: Pemilukada, Aplikasi, Android, Ionic Framework.

\section{PENDAhUluan}

Salah satu bentuk dari Gerakan Reformasi adalah pelaksanaan Pemilihan Umum Kepala Daerah (Pemilukada) baik di tingkat kabupaten kota maupun provinsi yang dilaksanakan secara langsung. Implikasi dari pelaksanaan pemilukada langsung adalah semakin banyaknya calon - calon yang bermunculan, terlebih ketika dibukanya peluang bagi calon perseorangan (independen) untuk ikut berlaga memperebutkan sebagai pemenangnya.

Dengan jumlah penduduk yang besar, sosial kemasyarakatan yang beragam, dan ketatnya persaingan, menjadikan Pemilukada sebuah proses yang menghabiskan energi dan tentu biaya besar. Dalam pandangan masyarakat, semakin banyak calon berarti semakin banyak pilihan. Sebaliknya, bagi para kandidat berarti persaingan yang semakin ketat. Butuh desain strategi yang jitu dan tepat agar perjalanan menuju kantor bupati atau walikota, gubernur bisa lebih efektif dan efisien.
E-Concept adalah sebuah Software Aplikasi alat terukur dalam perekrutan simpatisan Pemilukada sebagai alat ukur untuk memenangkan pemilu/pilkada dengan memanfaatkan teknologi informasi dan komunikasi dalam pengolahan data serta teknik statistika dalam membaca dan mendesain prediksi peluang bagi calon/kandidat. Membangun sinergi antara kekuatan politik dan kekuatan strategi pemenangan melalui pengolahan data. Dengan memanfaatkan sistem ini peta dan kekuatan kompetitor mudah diketahui, strategi pemenangan lebih terarah, proses kampanye terukur, dan hasil pemilu/pilkada lebih cepat diketahui. Sistem juga dilengkapi dengan aplikasi perhitungan cepat secara real count untuk melakukan mendapatkan hasil perhitungan suara yang akurat dan cepat.

Framework Ionic berbasis mobile merupakan kerangka kerja (framework) dari sebuah software yang bisa dijalankan di mobile operating system yang berbeda seperti Android, iOS dan Windows Phone. Konsep Ionic ini adalah membuat aplikasi yang dapat dijalankan pada sistem operasi 
yang berbeda. Ionic Framework adalah SDK (Software Development Kit) open source yang memungkinkan pengembang untuk membangun aplikasi mobile berkualitas tinggi menggunakan teknologi web yang familiar (HTML, CSS, dan JavaScript). Ionik difokuskan terutama pada tampilan dan nuansa, atau interaksi UI (User Interface), dari sebuah aplikasi (Griffith, 2017). Perancangan sebuah aplikasi berbasis mobile ditujukan bagi pengguna android dan iOS, karena ini dipilih model ionic framework. Dimana ionic framework merupakan sebuah mobile hybrid yang mampu digunakan di platform smartphone, seperti Android, iOS. Dibandingkan dengan framework jQuery, Ionic jauh lebih cepat.

Ionic menggunakan AngularJS, Node.js, SASS sebagai mesinnya. Seperti mobile framework kebanyakan, Ionic juga memiliki komponen/elemen CSS standar digunakan untuk smartphone, seperti button, list, card, form, range, tabs, grid dan lainnya. Cukup lengkap, walaupun masih terus dikembangkan. Ionic juga open source, jadi dapat digunakan untuk kebutuhan apapun. Selain itu Ionic memanfaatkan AngularJS untuk implementasi logikanya. Jika menggunakan jQuery terkenal lambat di mobile sedangkan Angular menawarkan performa dan respons cepat serasa aplikasi native (Rofiq and Putri, 2017).

\section{RUANG LINGKUP}

Di dalam penelitian ini permasalahannya mencakup:

1. Cakupan permasalahan dalam penelitian ini membahas tentang aplikasi pemenangan pilkada dan pileg untuk calon/kandidat kepala daerah baik tingkat kota/kabupaten maupun provinsi.

2. Batasan - batasan penelitian yang akan dibahas pada penelitian ini mencakup pada aplikasi perekrutan dan pendataan serta pemetaan calon pemilih tetap atau simpatisan pemilih baik untuk pilkada maupun pileg, dari data di lapangan kemudian dipetakan hasilnya secara visual grafik berdasarkan per TPS, kelurahan, kecamatan sampai dengan tingkat kabupaten/kotamadya.

3. Rencana hasil yang pemetaan simpatisan di lapangan Akan dijadikan prediksi untuk menentukan tingkat akurasi dan persentase pendukung calon/kandidat dalam pemilihan umum kepala daerah (pilkada) maupun pemilihan legislatif (pileg).

\section{KOMPONEN DAN METODE}

Penelitian ini dilakukan dengan penerapan aplikasi Hybrid menggunakan Framework Ionic dan Angular, yang dapat dijalankan pada sistem operasi yang berbeda, untuk menghasilkan efisiensi di dalam proses pembuatan aplikasi EConcept berbasis mobile.

\subsection{Ionic Framework}

Framework Ionic adalah sekumpulan teknologi yang dikembangkan untuk membangun aplikasi mobile hybrid yang powerful, cepat, mudah dan juga memiliki tampilan yang menarik. Ionic menggunakan AngularJS sebagai framework berbasis web dan menggunakan Cordova untuk membangun aplikasi mobile. Ionic Framework merupakan framework HTML5 yang masih baru, dirilis pada tahun 2018.

Framework ini sangat membantu di dalam mengembangkan aplikasi mobile dengan teknologi web seperti HTML, CSS dan JavaScript. Ionic platform menggunakan lisensi open source, boleh digunakan oleh siapa pun untuk membuat aplikasi free ataupun komersial dengan Ionic. Ionic memanfaatkan AngularJS untuk implementasi logikanya. Jika menggunakan jQuery terkenal lambat di mobile sedangkan Angular menawarkan performa dan respon cepat serasa aplikasi native (Rofiq and Putri, 2017).

\subsection{AngularJS}

AngularJS adalah iterasi selanjutnya dari AngularJS Framework. AngularJS Framework menjanjikan kinerja yang lebih baik dan menggunakan bahasa pemrograman Typescript untuk pemrograman yang aman. Sementara Apache Cordova memungkinkan pengembang membuat aplikasi mobile menggunakan JavaScript, CSS dan HTML daripada menggunakan platform antarmuka pemrograman aplikasi spesifik (APIS) seperti yang ada di iOS, Android atau Windows Phone. Ionic Framework adalah kit pengembangan perangkat lunak open source yang digunakan di untuk membuat aplikasi mobile hybrid. Dibangun dengan menggunakan AngularJS dan Apache Cordova (Muzakir and Hidiansah, 2018).

Ionic menyediakan pengguna dengan semua komponen, peralatan dan fungsi yang digunakan dalam pengembangan seluler asli - perangkat pengembangan perangkat lunak (SDKs). Pengembang bisa mendesain Aplikasi mereka menggunakan alat dan kode contoh yang disediakan oleh dokumentasi kerangka kerja dan bantuan situs web.

Instalasi itu membutuhkan NodeJS dan npm yaitu pengelola paket bawaan untuk NodeJS, terlepas dari Windows, lingkungan Linux atau Macintosh (Dunka, Emmanuel and Oyerinde, 2017a). Ionic adalah platform yang jauh lebih baik untuk digunakan dalam rangka merancang dan membangun aplikasi, karena aplikasi asli ada platform spesifik, memiliki alat pengembangan masing-masing, sangat memakan waktu dan mahal juga. Ionic on sisi lain adalah platform independen, menggunakan HTML, CSS dan JavaScript (Chaudhary, 2018). Proses pembangunannya cukup cepat dan pengembang memiliki akses langsung $A P I$ dengan Cordova.

\subsection{JavaScript}

JavaScript adalah bahasa pemrograman serbaguna, dapat digunakan untuk membuat suatu program sebagaimana dapat dibuat dengan bahasa pemrograman lain seperti Pascal atau $\mathrm{C}++$. JavaScript mendukung sumber daya internet Worldwide Web atau yang biasa disebut dengan Web, mendukung aplikasi klien/server, baik dalam jaringan lokal(LAN) maupun jaringan (WAN). Dalam sejumlah literatur disebutkan bahwa JavaScript merupakan hasil perpaduan sifat dari sejumlah bahasa pemrograman, yaitu $\mathrm{C}, \mathrm{C}++$, Object-C, dan lain-lain. 
Selain itu JavaScript dilengkapi dengan unsur keamanan, yang tak kalah penting adalah bahwa JavaScript menambahkan paradigma pemrograman sederhana, jika mengenal bahasa pemrograman $\mathrm{C}$ atau $\mathrm{C}++$, yang mengandalkan pointer dan merasakan kerumitan nya, JavaScript justru meninggalkannya, sehingga akan diperoleh kemudahan saat menggunakannya. JavaScript adalah bahasa pemrograman yang dapat memegang kontrol aplikasi, berorientasi objek murni dan digunakan secara prosedural. JavaScript merupakan bahasa yang case sensitive seperti halnya bahasa pemrograman JavaScript yaitu membedakan penulisan dengan huruf kecil dan huruf besar memberi arti yang berbeda.

JavaScript menggunakan kelas untuk membentuk suatu objek. Sejumlah kelas sudah tersedia dan dapat digunakan dengan mudah, bahkan dapat dikembangkan jauh melebihi konsep pewarisan, yang dimaksud pewarisan adalah sifat yang ada pada bahasa pemrograman berorientasi objek yang memungkinkan sifat-sifat suatu objek diturunkan dengan mudah ke objek lain (Rofiq and Putri, 2017).

\subsection{PHP dan MySQL}

PHP (Hypertext Pre-processor) pemrograman interpreter yaitu proses penerjemahan baris kode sumber menjadi kode mesin yang dimengerti komputer secara langsung pada saat baris kode dijalankan, disebut juga sebagai pemrograman Server Slide Programing, hal ini dikarenakan seluruh prosesnya dijalankan oleh server. PHP adalah program yang dikembangkan secara bersama oleh para programmer dari seluruh dunia yang menekuni dunia open source, PHP dikembangkan khususnya untuk mengakses dan memanipulasi data yang ada di database server open source seperti MySQL karena memiliki tingkat kompatibilitas yang sangat baik.

PHP mengenal pengolahan data menggunakan file teks, tetapi menyimpan data dalam file biasa memiliki banyak keterbatasan. File teks tidak memiliki kemampuan mengolah data seperti menghitung total nilai, rata - rata, dan sebagainya, untuk itulah diperlukan database seperti MySQL, dengan database program akan lebih mudah mengendalikan akses terhadap data. MySQL atau dibaca "MySekuel" adalah suatu relational database management system yaitu: aplikasi sistem yang menjalankan fungsi pengolahan data. MySQL merupakan salah satu data base terbesar yang digunakan dalam pengolahan data di dunia. Hal ini terbukti digunakannya MySQL oleh beberapa perusahaan dan institusi besar dunia seperti NASA,Yahoo! Finance, Aizawa (Japanese Security), dll. (Rofiq and Putri, 2017).

Prosedur instalasi dari Ionic dan Cordova cukup sederhana. Sebelum instalasi Ionic dan Cordova diharapkan agar melakukan instalasi Node JavaScript terlebih dahulu dimana source bisa di download pada nodejs.org. Untuk melakukan instalasi global, perintah berikut dapat di masukan di terminal yang telah menginstal paket yang dibutuhkan.
Pemasangan global: npm install -g ionic cordova Setelah aplikasi dasar Ionic sudah ter-install, silahkan gunakan command berikut untuk pengecekan (Gupta, 2016):

Ionic $-v$

Cordova-v

Untuk membangun aplikasi baru di Ionic, ionic serve dapat digunakan di terminal setelah melakukan setting direktori yang sesuai dimana proyek tersebut tersimpan. Hasil dari perintah tersebut akan menghasilkan tampilan aplikasi pada browser default pada computer (Dunka, Emmanuel and Oyerinde, 2017b). Jika ingin menampilkan hasil aplikasi dengan berbagai versi pada browser bisa menggunakan ionic serve -cls , maka akan tampil 3 versi tampilan yaitu Android, Windows dan iOS (Pradana and Waspada, 2019).

Untuk menjalankan aplikasi pada emulator/device phone harus menambahkan platform pada project aplikasi dengan cara : ionic platform add [android/iOS], pada terminal. Ketika ingin menjalankan aplikasi pada emulator bisa menggunakan command : ionic [run/emulate] [android/iOS].

\subsection{Pengembangan Aplikasi Hybrid}

Pengembangan aplikasi mobile cukup bergantung terhadap sistem operasi ponsel itu sendiri (Dewanti and Permana, 2017). Contohnya, jika Anda ingin mengembangkan aplikasi untuk sistem operasi Android, maka Anda dapat menggunakan tool Android Studio dengan menggunakan bahasa pemrograman JavaScript. Namun, apabila Anda ingin mengembangkan aplikasi untuk sistem operasi iOS, tool yang dapat Anda gunakan adalah Apple Xcode dengan bahasa pemrograman Swift atau Objective-C. Aplikasi hybrid adalah aplikasi yang menggabungkan teknologi aplikasi web dan aplikasi native, tetapi tampilan dan cara kerja aplikasi hybrid lebih seperti aplikasi web daripada aplikasi mobile.

Melalui pendekatan hybrid, pengembang mengodekan framework nya sendiri, mengambil keuntungan dari alat pengembang yang sudah ada. Aplikasi hybrid dibangun menggunakan HTML5, dan tidak memerlukan pengetahuan yang terperinci bagi target platform. Pendekatan hybrid mengambil keuntungan dari browser dan kemampuan perangkat mobile. Pendekatan hybrid dapat digunakan untuk aplikasi yang didukung dengan server maupun aplikasi standalone.

Keuntungan utama dari pendekatan hybrid adalah penggunaan antarmuka user di platform yang berbeda memanfaatkan fitur platform native. Aplikasi dapat menggunakan fitur perangkat native yang tersedia menggunakan API (Pradana and Waspada, 2019).

Dengan bantuan Ionic Framework, dapat dikembangkan aplikasi dengan fungsionalitas lengkap yang dapat dijalankan di mobile operating system yang berbeda seperti Android, iOS dan Windows Phone. Dapat disimpulkan bahwa Ionic sebagai teknologi baru, namun sangat berkembang, adalah sederhana dan mudah digunakan.

Ionic framework memungkinkan pengembang untuk membuat kode pada Typescript, HTML dan CSS untuk 
menghasilkan aplikasi lintas platform hybrid yang secara penuh memiliki fungsional bagi pengguna seperti yang terlihat pada gambar 1 dibawah. Menciptakan teknologi yang efektif, dengan di mediasi melalui pendekatan prototype (prototyping) dimana pengembangan dan pengujian terhadap model kerja (prototipe) dari aplikasi yang dikembangkan telah melalui proses interaksi secara berulang dan melalui perbaikan terus-menerus hingga tercapai kesesuaian dengan yang dibutuhkan oleh pengguna (user).

Aplikasi yang tepat tentunya sangat membantu pengguna dalam kelancaran maupun kecepatan penyelesaian berbagai tugas, baik dalam skala kecil atau besar (Sucipto $d k k ., 2018$ ) bisa dilihat pada gambar 1.

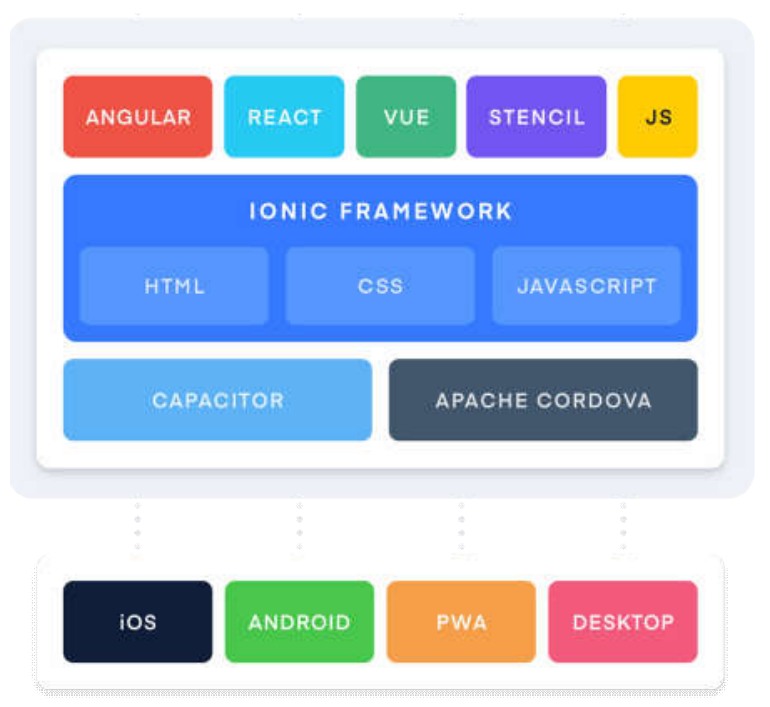

Gambar 1. Stack Teknologi Ionic Framework

Dalam implementasi di masa depan, pengguna akan dapat mengakses melalui aplikasi yang diinstal di smartphone untuk kebutuhan pelaporan bencana alam. Seluruh proses dalam aplikasi ini akan selalu terhubung menggunakan internet untuk dapat menggunakannya. Dalam kasus permintaan dan tanggapan, data akan melibatkan modul antarmuka pemrograman aplikasi $(A P I)$, dalam modul $A P I$ mencakup fungsi permintaan basis data (Waranashiwar and Ukey, 2018).

Menurut Roy Thomas Fielding, REST (Representational State Transfer) merupakan arsitektur aplikasi perangkat lunak yang memodelkan cara data direpresentasikan, diakses, dan dimodifikasi pada web. Data dan fungsi pada arsitektur REST diakses dengan menggunakan Uniform Resource Identifiers (URIs) dan dianggap sebagai sumber daya.

URIs biasanya merupakan link pada web. Arsitektur REST merupakan arsitektur client-server, dan dirancang untuk menggunakan protokol komunikasi stateless, biasanya berupa HTTP. Pada arsitektur REST, antarmuka dan protokol standar digunakan client dan server untuk menukarkan representasi sumber daya yang ada (Pradana and Waspada, 2019).

Selain itu ada juga dasbor untuk masuk sebagai administrator untuk memperbarui semua konten aplikasi pemetaan koordinator, sukarelawan, dan simpatisan tersebut. Berikut gambaran mengenai alur aplikasi yang diterapkan pada Gambar 2.

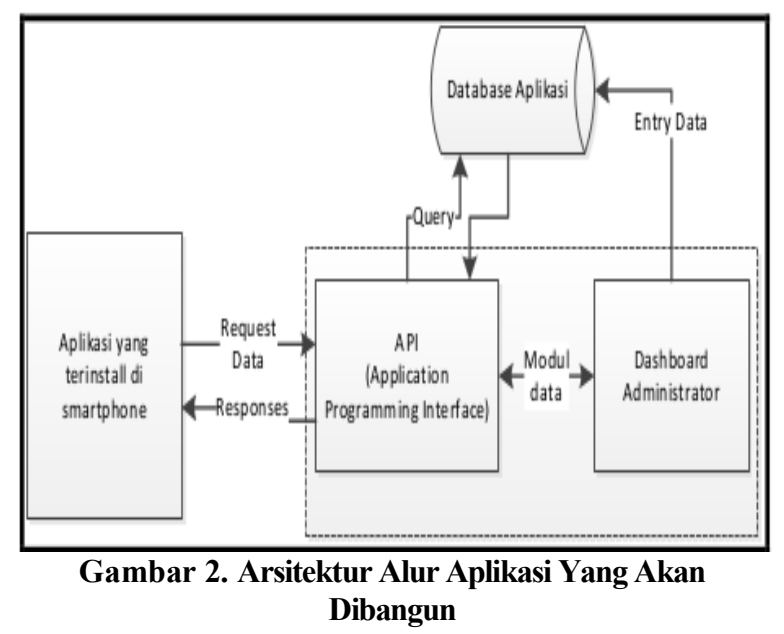

\section{PEMBAHASAN}

Aspek terpenting untuk melakukan kode pada aplikasi mobile adalah pemahaman yang mendalam tentang Angular JavaScript Framework. Terdapat berbagai aspek yang perlu dipahami untuk dapat memahami pengembangan aplikasi menggunakan Ionic dan Angular JavaScript seperti NgModule, component, dan HTML Angular dibangun untuk memberikan fungsionalitas pada aplikasi. Angular juga memungkinkan untuk menentukan component kita sendiri. NgModule pada Angular digunakan untuk mengendalikan data dalam aplikasi dimana digunakan objek Typescript dasar.

Controller setiap page HTML dikendalikan pada code Typescript. Penggunaan Ionic Framework dan Angular terbukti dapat dijalankan di mobile operating system yang berbeda.. Untuk menguji bahwa Ionic telah running di cross platform dapat menggunakan kode sebagai berikut:

1. Pada Android: ionic run android

2. Pada iOS : ionic run iOS

Dilihat dari sisi simulasi dalam bentuk web-based yang dimiliki Ionic, dapat menggunakan kode: ionic serve - cls, maka akan tampil di browser tampilan beda platform (Sucipto $d k k$., 2018). Aplikasi menggunakan dua model yaitu backend yang menggunakan PHP dan MySQL, sedangkan untuk tampilan front end dengan modul komunikasi Application Program Interface (API) untuk terhubung ke database seperti terlihat pada gambar 3 dibawah ini. 


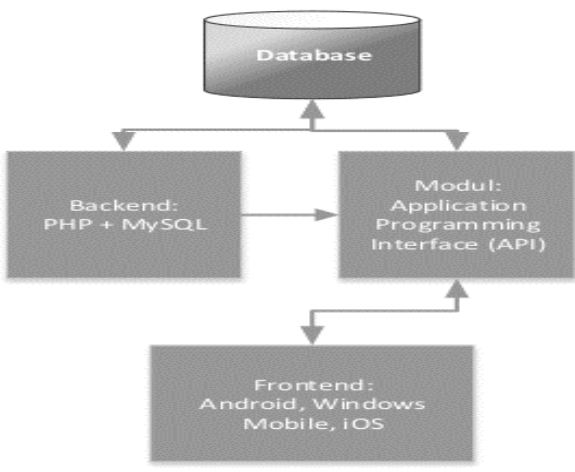

Gambar 3. Alur Pengaksesan Dalam Aplikasi

Setelah merancang user-interface dan membuat panggilan $A P I$, pengembangan aplikasi tahap akhir siap untuk di-deploy. Pengembangan akhir aplikasi pada platform mobile dapat dilihat di bawah ini yang mengekstrak data real time dan menampilkannya ke pengguna untuk mengetahui situasi layanan yang sedang digunakan. Penulis menggunakan API Free dari www.ibacor.com untuk percobaan pembuatan aplikasi EConcept yang mempunyai beberapa hak akses di dalam setiap penggunanya yaitu; sebagai sukarelawan, koordinator, kandidat dan administrator. Tampilan form login aplikasi terlihat pada gambar 4 dibawah ini.

Aplikasi juga terdiri dari dua versi yaitu; versi pertama adalah web based yang digunakan oleh operator maupun administrator untuk melakukan monitoring dan validitas setiap data yang masuk ke server. Sedangkan versi kedua versi mobile berbasis android yang terinstal pada pengguna dengan hak akses sukarelawan yang akan dipakai dalam proses perekrutan simpatisan di lapangan seperti pada gambar 4 .

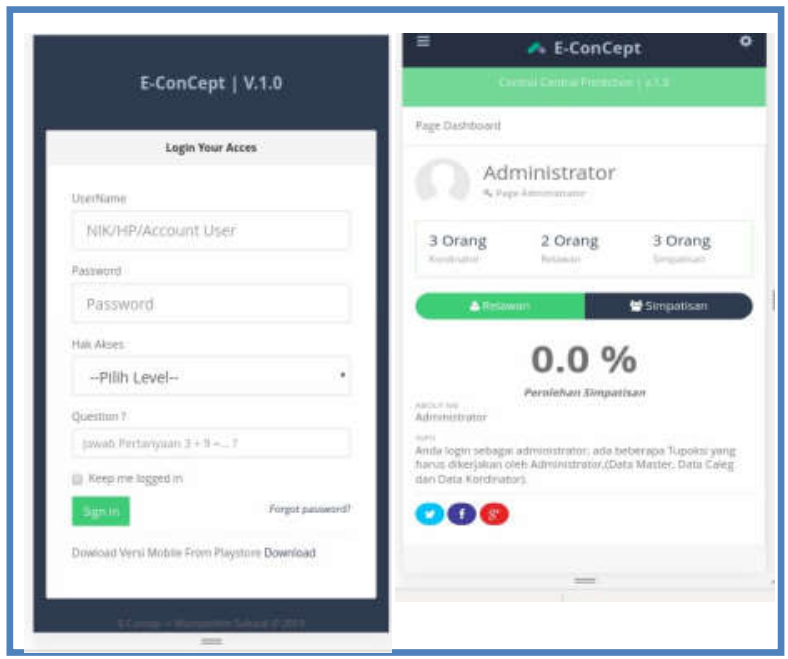

Gambar 4. User Interface Aplikasi
Pemetaan data simpatisan dapat di visualisasi kedalam bentuk grafik per kelurahan, kecamatan sampai dengan kabupaten/kotamadya seperti tampak pada gambar 5 dibawah ini. Sehingga dapat di analisis wilayah dimana saja yang merupakan basis dari kekuatan dan kelemahan calon kandidat. Sampai pada akhirnya kandidat dapat menentukan strategi apa yang akan dilakukan berikutnya.

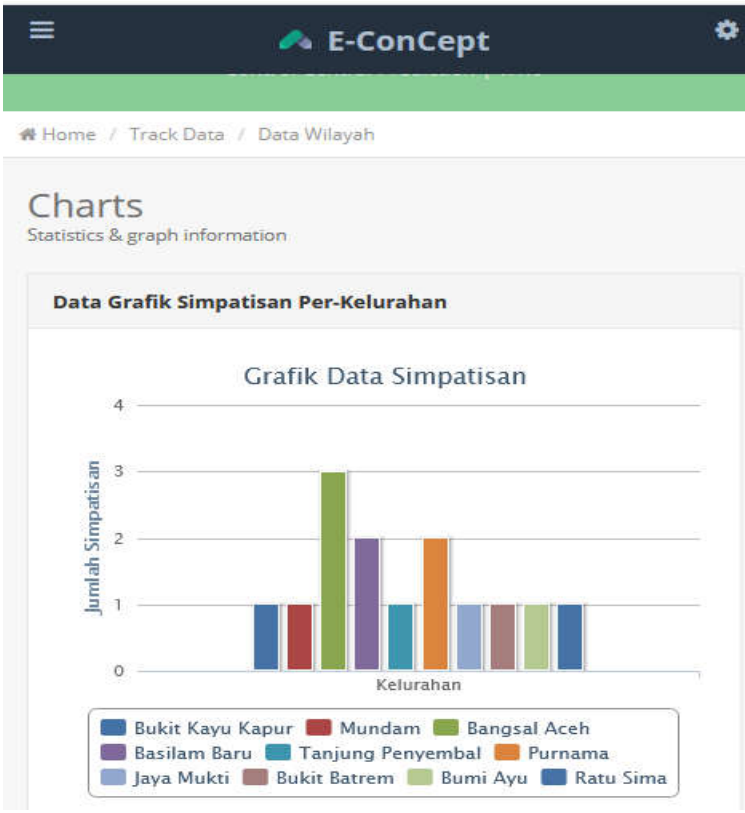

Gambar 5. Tampilan Grafik Data Simpatisan

Grafik pada gambar 5 diatas diambil secara real-time dari data para sukarelawan dan koordinator di lapangan melalui proses perekrutan dengan melakukan metode door to door dengan input nomor induk kependudukan (NIK) dan disertai upload foto simpatisan sebagai bahan pendukung validitas datanya. Sehingga diharapkan dengan adanya upload gambar/foto simpatisan nantinya akan terlihat valid atau tidaknya data yang masuk kedalam server.

Setiap data masuk yang telah di verifikasi dan di validasi oleh operator akan ditampilkan secara real-time dan visual melalui grafik per kelurahan, kecamatan sampai ke tingkat kabupaten/kotamadya. Dari grafik tersebut juga nantinya akan dapat terlihat pemetaan daerah atau wilayah dimana saja yang merupakan basis kekuatan dari calon/kandidat kepala daerah. Dengan demikian, maka calon kepala daerah/kandidat dapat menyusun strategi bagaimana cara memenangkan pemilu secara akurat dan valid berdasarkan dari hasil dan analis data yang masuk melalui aplikasi para sukarelawan dan koordinator di lapangan.

Dari rakap data secara visualisasi dalam bentuk grafik tersebut seorang kandidat sudah mendapatkan gambaran secara umum dan bisa memprediksi apakah dirinya akan menang atau kalah. Selain daripada itu tentunya aplikasi juga masih bisa dijadikan alat ukur dan referensi di masa yang akan datang jika ingin melakukan pencalonan kembali atau tidak berdasarkan 
jumlah simpatisan yang telah di rekrut serta dapat melakukan perbaikan-perbaikan strategi lainnya.

\section{KESIMPULAN}

E-Concept adalah Software Aplikasi perekrutan simpatisan Pemilukada dan sebagai alat yang terukur untuk memenangkan pemilu/pilkada dengan memanfaatkan teknologi informasi dan komunikasi dalam pengolahan data serta teknik statistika dalam membaca dan mendesain prediksi peluang bagi calon atau kandidat. Dengan bantuan Ionic Framework, dapat dikembangkan aplikasi dengan fungsionalitas lengkap yang dapat dijalankan di mobile operating system yang berbeda seperti Android, iOS dan Windows Phone. Dapat disimpulkan bahwa framework Ionic sebagai teknologi baru, namun sangat berkembang, adalah sederhana dan mudah digunakan. Ionic memungkinkan pengembang untuk membuat kode pada Typescript, HTML dan CSS untuk menghasilkan aplikasi lintas platform hybrid yang secara penuh memiliki fungsional bagi pengguna.

Menciptakan teknologi yang efektif, dengan di mediasi melalui pendekatan prototype dimana pengembangan dan pengujian terhadap model kerja dari aplikasi yang dikembangkan telah melalui proses interaksi secara berulang dan melalui perbaikan terus-menerus hingga tercapai kesesuaian dengan yang dibutuhkan oleh pengguna. Dengan adanya dukungan sebuah aplikasi yang tepat tentunya sangat membantu pengguna dalam kelancaran maupun kecepatan penyelesaian berbagai tugas, baik dalam skala kecil atau besar. Sehingga dapat menghemat biaya dan mempercepat hasil pekerjaan sesuai dengan yang diharapkan.

\section{SARAN}

Hasil penelitian dapat digunakan sebagai salah satu referensi di dalam pengembangan perangkat lunak, baik di Indonesia maupun dalam skala global, untuk melakukan efisiensi di dalam proses pembuatan perangkat lunak berbasis mobile. Penelitian ini dilakukan pada sebatas prototype sistem, sehingga untuk proses penelitian selanjutnya dapat diimplementasikan dan dilakukan analisis serta evaluasi sistem yang lebih detail. Aplikasi ini dapat dikembangkan lebih lanjut menggunakan framework lain selain Ionic dengan penambahan fitur seperti whatsapp blast, social media, sms centre API dan real count. Sehingga aplikasi dapat akomodasi banyak fitur sesuai dengan kebutuhan dan kondisi perubahan teknologi terkini.

\section{DAFTAR PUSTAKA}

Chaudhary, P. 2018. 'Ionic Framework', International Research Journal of Engineering and Technology, 05(05), pp. 3181-3185.

Dewanti, P. and Permana, P. A. G. 2017. 'Pengembangan Aplikasi Hybrid Menggunakan Ionic 2 Framework dan Angular 2', E-Proceedings KNS\&I STIKOM Bali, pp. 396-400.

Dunka, B., Emmanuel, E. and Oyerinde, Y. 2017. 'Hybrid Mobile Application Based on Ionic Framework Hybrid Mobile Application Based on Ionic Framework Technologies', (January 2018), pp. 3-4. doi: 10.13140/RG.2.2.17143.57765.

Griffith, C. 2017. Mobile App Development with Ionic, Revised Edition: Cross-Platform Apps with Ionic, Angular, and Cordova. " O'Reilly Media, Inc.".

Gupta, A. and Gaffar, A. 2016. "Hybrid Application Development using Ionic Framework \& AngularJS', International Journal of Innovative Research in Computer Science \& Technology, 4(2), pp. 62-64.

Muzakir, A. and Hidiansah, E. 2018. 'Mobile Hybrid Application Sebagai Solusi Dalam Pelaporan Bencana Menggunakan Framework Cordova', Jurnal Informatika: Jurnal Pengembangan IT, 3(2), pp. 242-248. doi: 10.30591/jpit.v3i2.864.

Pradana, D. I. and Waspada, I. 2019. 'Aplikasi Hybrid Pada Sistem Informasi Penyewaan Buku', Simetris: Jurnal Teknik Mesin, Elektro dan Ilmu Komputer, 10(1), pp. 1-14. doi: 10.24176/simet.v10i1.2600.

Rofiq, M. and Putri, S. I. 2017. 'Perancangan Sistem Pemesanan Rumah Sakit di Kota Malang Menggunakan Ionic Framework berbasis Mobile Phone', Jurnal Ilmiah Teknologi Informasi Asia, 11(2), p. 171. doi: 10.32815/jitika.v11i2.210.

Sucipto, A. et al. 2018. 'Penerapan Aplikasi Mobile Information Karimun Island Menggunakan Ionic Framework', JTET (Jurnal Teknik Elektro Terapan), 7(1), pp. 1-30.

Waranashiwar, J. and Ukey, M. 2018. 'Ionic Framework with Angular for Hybrid App Development', (5), pp.1-2.

\section{UCAPAN TERIMA KASIH}

Terima Kasih kepada Calon/Kandidat Walikota Dumai untuk PILKADA Kota Dumai 2020 yang bersedia memberikan kontribusi material maupun pemikiran sehingga aplikasi E-Concept ini bisa di diimplementasikan dalam Pemenangan Pilkada baik tingkat Kapubaten/kotamadya maupun Provinsi. 